\title{
ANALYSIS OF LEARNING DESK DESIGN FOR CHILDREN MENTAL RETARDATION AT EXTRA ORDINARY SCHOOL OF PUTRA MANDIRI, CILACAP
}

\author{
${ }^{1}$ Supri Atin ${ }^{1},{ }^{2}$ Dwi Aries Himawanto, ${ }^{3}$ Nunuk Suryani \\ 1,2,3 Magister Pendidikan Luar Biasa, Universitas Sebelas Maret, Surakarta, Indonesia
}

\begin{abstract}
The design of study desks in special schools is generally made equal to the purpose for the convenience of students in learning so as to help students in receiving the lessons well. The purpose of this study was to analyze and redesign the table in grade IV child tunagrahita. This research uses descriptive qualitative method through exploration approach. This study used observation and unstructured interviews with headmasters, classroom teachers, students of grade IV tunagrahita students at SLB Putra Mandiri Kawunganten in Cilacap. The result of this research is proposed in the form of analysis of table design for learners so as to produce more ergonomic desk.
\end{abstract}

Keywords: mentally disabled, anlysis desain, table, accessbility

\section{Latar Belakang}

Sekolah adalah tempat berinteraksi antara guru dan siswa dalam belajar. Pengertian sekolah sendiri adalah suatu lembaga yang memang dirancang khusus untuk pengajaran para murid (siswa) di bawah pengawasan para guru. Seperti yang diungkapakan oleh Nurlita Anugrahing Widi, Rullan Nirwansyah (2013) Bahwa sekolah khusus atau sekolah luar biasa perlu mengutamakan aksesbilitas sirkulasi maupun desain dari interior hingga ekseriornya, sehingga pencpaian rasa aman dan nyaman dalam melakukan aktitivitas belajar mengajar dapat terlaksana. Sekolah tidak hanya untuk anak regular namun juga untuk anak berkebutuhan khusus sehingga sekolah tidak hanya memikirkan kebutuhan akan kognitif peserta didik namun juga harus memperhatikan sarana dan prasarana guna menunjang pembelajaran.

* Corresponding author: Supri Atin

ochiattin@gmail.com

Published online at http://IJDS.ub.ac.id/2018

Copyright @ 2018PSLD UB Publishing. All Rights Reserved
Pendapat ini didukukung oleh Tamba Jeftri (2016) aksesbilitas sebuah infrstruktur pada sebuah bangunan merupakan hal yang paling penting untuk menunjang keamanan dan kenyamanan semua orang yang ada didalanya. Sekolah adalah kegiatan di waktu luang bagi anak-anak di tengah kegiatan mereka yang utama, yaitu bermain dan menghabiskan waktu menikmati masa anak-anak dan remaja. Kegiatan dalam waktu luang ialah mempelajari cara berhitung, membaca huruf-huruf dan mengenal tentang moral (budi pekerti) dan estetika (seni).

Jadi sekolah adalah sebuah tempat pendidikan untuk mendidik anak belajar, dari yang tidak bisa menjadi bisa dan dari yang tidak tahu menjadi tahu. Pendidikan disekolah akan maju jika didukung dengan sarana dan prasaran yang memadai, yang memberikan kenyamanan dan pastinya kebermanfaatan sesuai fungsinya. Setiap sekolah pastinya dibangun dan dirancang berdasarkan kenyamanan dan keamanan bagi warga sekolah sesuai undang - undang yang berlaku. Bagian - bagian sekolah seperti ruang kelas, kantor, perpustakaan, koridor, tangga, kamar mandi, dapur, uks, ruang ketrampilan , tidak semuanya 
dirasa nyaman dan aman oleh peserta didik dan warga sekolah lainnya. Meubeler seperti meja terkadang terlupakan dalam desain sekolah.

Anak berkebutuhan khusus adalah anak yang membutuhkan layanan khusus maka fasilitas yang ada disekolahpun disesuikan dengan kebutuhan peserta didik. Namun tidak semua sarana dan prasarana yang ada di sekolah sesuai dengan keamanan dan kenyamanan anak berkebutuhan khusus. Salah satu anak berkebutuhan khusus adalah anak tunagrahita. Tunagrahita adalah istilah yang digunakan untuk menyebut anak yang mempunyai kemampuan intelektual di bawah rata - rata, E. Kosasih (2012:139). Sejalan dengan pendapat itu bahawa tunagrahita adalah anak yang memiliki problem belajar yang disebabkan adanya hambatan perkembangan intelegensi mental, emosi social dan fisik, Bandi Delphie (2006:2). Dari pengertian tersebut bisa dijelaskan bahwa anak tunagrahita adalah anak dengan IQ rendah, serta memiliki hambatan perkembangan emosi social dan fisik.

Meubeler sekolah sebagai prasarana yang menunjang keberhasilan belajar di dalam kelas, salah satunya adalah meja. Meja digunakan anak sebagai landasan untuk menulis, menaruh buku, pensil, penggaris, penghapus dan sebagainya. namun pada kenyataannya tidak semua sekolah memiliki meja yang ideal sesuai dengan kebutuhan anak berkebutuhan khusus dan salah satunya adalah SLB Putra Mandiri. Sekolah yang belum lama berdiri ini memiliki tujuh kelas, dari masing - masing kelas memiliki meja yang berbeda - beda bahkan ada kelas yang tidak menggunakan meja. Hal ini menyulitkan peserta didik untuk belajar menulis sehingga sebagian dari peserta didik ketika menulis dengan tiduran atau rebahan. Keadaan seperti ini sangat tidak nyaman untuk belajar karena peserta didik akan cepat lelah dan lambat laun akan mengakibatkan kelainan tulang punggung.

\section{Kajian Pustaka}

Ergonomi berasal dari bahasa latin yaitu ergon (kerja) dan nomos (hukum alam ) dan dapat didefinisikan sebagai studi tentang aspek - aspek manusia dalam lingkungan kerjanya yang ditinjau secara anatomi, fisiologi, psikologi, engginering, manajemen dan desain / perancangan, Nurmianto (2008). Ergonomi berasal dari kata Yunani ergon yang artinya kerja dan nomos yang berarti aturan, secara keseluruhan ergonomi berarti aturan yang berkaitan dengan kerja, sasaran penelitian ergonomi adalah manusia pada saat bekerja dalam lingkungannya. Secara singkat dapat dikatakan bahwa ergonomi ialah penyesuaian tugas pekerjaan dengan kondisi tubuh manusia dengan tujuan untuk menurunkan stress yang akan dihadapi, yaitu dengan cara menyesuaikan ukuran tempat kerja dengan dimensi tubuh agar tidak melelahkan, pengaturan suhu, cahaya dan kelembaban betujuan agar sesuai dengan kebutuhan tubuh manusia.

(http://ratnawulandari12.blogspot.co.id/, di unduh tanggal 19 oktober 2017). sedangkan demenurut (Wignosubroto 2008) Ergonomi adalah suatu cabang keilmuan yang sistematis untuk memanfaatkan informasi - informasi mengenai sifat, kemampuan dan keterbatasan manusia untuk merancang suatu system kerja sehingga orang dapat hidup dan bekerja pada system tersebut dengan baik, yaitu melalui pekerjaan itu dengan efektif, efisien, aman dan nyaman,

Dari pengertian - pengertian ergonomi diatas dapat disimpulkan bahwa ergonomi adalah ilmu yang digunakan untuk menggali, menerapkan informasi-informasi mengenai perilaku manusia, kemampuan, keterbatasan dan karakteristik manusia lainnya untuk merancang peralatan yang dibutuhkan dalam pekerjaan dan lingkungan guna meningkatkan produktivitas, keselamatan kenyamanan dan efektivitas pekerjaan manusia.

\section{Meja}

Meja adalah salah satu bagian prasarana dalam sekolah. Seperti yang diungkapakan Patina Harahap, Listiani Nurul Huda, Sugih Arto Pujangkoro (2013) meja merupakan salah satu fasilitas sekolah berupa permukaan datar yang disokong oleh beberapa kaki da nada yang memiliki laci. Namun kurangnya pengetahuan dan dana untuk membuat sarana maupun aksesbilitas yang baik mempengaruhi proses pembelajaran bagi anak berkebutuhan khusus, (Abwatie al khakim, Donni Prakosha, Dwi A Himawanto, 2017) Mebeler ini sangat dibutuhkan peserta didik guna menunjang 
pembelajaran yang efektif, nyaman dan aman sehingga tercipta suasana belajar yang menyenangkan dan mencapai tujuan pembelajaran. Ukuran dan bentuk meja pada umumnya standar sesuai aturan yang berlaku. Meja sangat berpengaruh pada pebelajaran siswa dikelas. Ketika anak - anak sedang tidak focus biasanya akan memunculkan gerak gerik tersendiri seperti usil degan teman, memancing keramaian dikelas, duduk dengan posisi yang sakah. Jika hal ini berlanjut terus maka bisa menyebabkan gangguan perkembangan tubuhnya. Seperti:

a. Kelainan ditulang belakang yakni kifosis, lordosis, dan skoliosis

b. Kelainan pada mata seperti yang terjadi pada umumnya yaitu miopi atau rabun jauh. Hal ini dikarenakan posisi duduk mempengaruhi jarak pandang mata dengan objek.

c. Kondisi tubuh menjadi cepat lelah

d. Sulitnya peserta didik untuk konsentrasi

\section{Metodologi}

1) Tahap perencanaan

Perencanaan dimualai dengan melihat kondisi meja yang ada diruang kelas anak tunagrahita yang harus diperbaiki karena kurang sesuai dengan kebutuhan, sehingga adanya desain usulan. Data yang diambil berdasarkan kebutuhan peserta didik dari hasil wawancara dan gambar meja yang ada diruang kelas sebagai objek penelitian.

2) Tahap tindakan

Pada tindakan melakukan sketsa redesain sebagai usulan meja berdasarkan data yang ada.

3) Tahap observasi

Pada tahap observasi melakukan pengamatan terhadap meja untuk menghasilkan re-desain yang sesuai sehingga dapat dilakukan refleksi dan revisi terhadap rencana tindakan yang telah dilakukan untuk menyusun rencana berikutnya.

4) Tahap refleksi

Pada tahap refleksi analisis terhadap semua informasi yang diperoleh dari pelaksanaan tindakan sehingga dapat dipahami dan dicari makna terhadap proses dan pelaksanaan tindakan sebagai dampak adanya tindakan tersebut.

\section{Hasil Pembahasan}

Dari data yang diperoleh, peserta didik kelas 4 anak tunagrahita di salah satu SLB swasta di cilacap belajar menggunakan meja tanpa kursi. Pembelajaran seperti ini kurang, tidak nyaman dan aman. Sebagian dari mereka belajar dengan membungkukkan badan pada posisi duduk dan sebagian lagi dengan rabahan. Jika hal ini berlangsung terus menerus maka akan menghambat pembelajaran dan menyebabkan kelainan tulang belakang. Disamping itu, mereka juga sering kehilangan barang miliknya seperti pensil, penghapus dan penggaris karena tercecer. Maka usulan re-desain meja sebagai hasil wawancara dengan peserta didik dan guru kelas anak tunagrahita di jelaskan sebagai berikut:

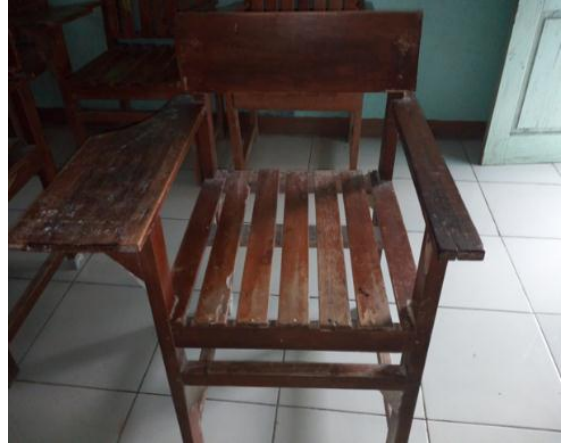

a. Meja kelas 3 tunagrahita

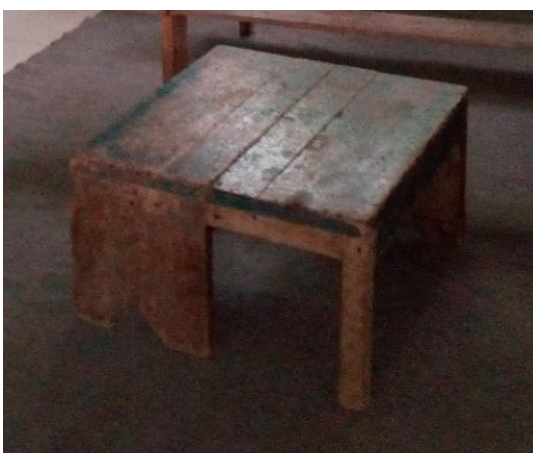

b. Meja kelas 4 dan 5 tunagrahita 


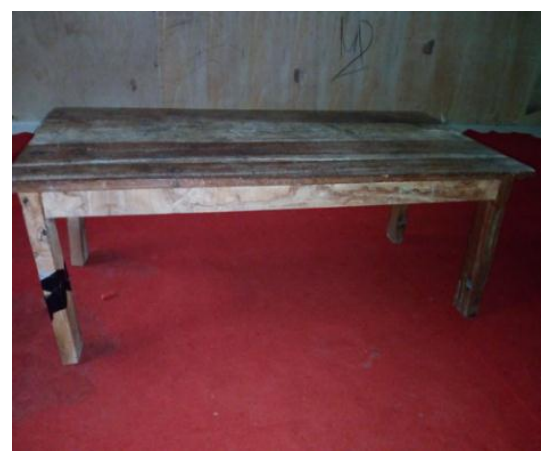

c. Meja kelas 1 tunagrahita

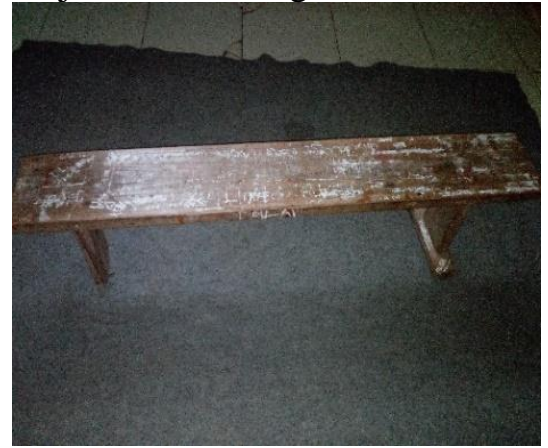

d. Meja kelas 2 tunagrahita

Meubeler di beberapa kelas SLB kurang memenuhi syarat kenyamanan dan keamanan bagi peserta didik. Desain meja yang kurang nyaman dan aman digunakan oleh peserta didik menyebabkan peserta didik kurang semangat dalam belajar. Belajar menggunakan meja membuat konsentrasi peserta didik meningkat. Belajar sambil tengkurap atau tiduran diatas lantai membuat tubuh peserta didik cepat pegal dan sakit. Ketika peserta didik belajar dengan tengkurap dan sudah merasa sakit maka ia akan malas meneruskan belajarnya. Posisi belajar yang tidak nyaman juga akan menganggu kesehatan tubuh, seperti kelainan pada tulang belakang. Disamping itu banyak peralatan sekolah peserta didik yang tercecer, tertukar dengan teman dan juga tertinggal di kelas. Mereka juga sering keluar masuk degan alasan mengambil minum.

Dengan mengamati pembelajaran yang ada di SLB Putra Mandiri Kawunganten maka perlu re-desain meja tanpa kursi yang bisa membuat anak nyaman. Meja tersebut perlu didesaian dengan cermat seperti adanya tempat minum, tempat pensil, tempat penghapus dan penggaris dengan maksud peralatan anak terjaga sehingga tidak tercecer atau tertukar satu dengan yang lainnya. Dalam desain meja yang ada di SLB Putra Mandiri Kawunganten tidak ada standar baku yang digunakan. Ukuran meja yang ada di kelas 4 dan 5 tunagrahita seperti gambar di b. kelas tunagrahita adalah mejanya dengan panjang $55 \mathrm{~cm}$ namun mengecil pada panjang $30 \mathrm{~cm}$, lebar depan meja $21 \mathrm{~cm}$ lebar belakang meja $5 \mathrm{~cm}$, tinggi meja dari kursi $25 \mathrm{~cm}$ dan ukuran kursi dengan panjang $55 \mathrm{~cm}$, lebar $50 \mathrm{~cm}$, tinggi $43 \mathrm{~cm}$, tinggi sandaran kursi $80 \mathrm{~cm}$, lebar $55 \mathrm{~cm}$. Meja ini dirasa kurang nyaman oleh peserta didik karena meja berada disamping kursi sehingga menyulitkan peserta didik untuk menulis, disamping itu luas meja yang kecil tidak sebanding dengan ukuran kursi bagi peserta didik tunagrahita. Kursi ini dirasa terlalu besar, lebar dan tinggi sehinga kaki peserta didik menggantung di kursi tidak napak dilantai. Saat belajar, peserta didik tunagrahita sering menghadapkan badan ke meja yang berada disamping kursi, mereka memasukan kakinya ke bawah meja agar dapat belajar dengan nyaman.

Pada gambar a. Meja kelas 3 tunagrahita dengan tinggi $33 \mathrm{~cm}$, panjangn $74 \mathrm{~cm}$, lebar $55 \mathrm{~cm}$, tinggi ruang bawah $26 \mathrm{~cm}$, panjang ruang bawah $64 \mathrm{~cm}$, lebar ruang bawah $46 \mathrm{~cm}$ dan ukuran meja yang lainnya adalah panjang $120 \mathrm{~cm}$, lebar $25 \mathrm{~cm}$ dan tinggi $30 \mathrm{~cm}$. diraasa lebih nyaman dengan karena ketinggian meja dengan peserta didik sesuai. Anak - anak dikelas ini lebih terlihat aktif menulis.

Pada gambar c. anak kelas 1 tunagrahita dengan tinggi $30 \mathrm{~cm}$, panjang meja $100 \mathrm{~cm}$, lebar $20 \mathrm{~cm}$, tinggi ruang bawah $28 \mathrm{~cm}$, panjang ruang bawah 96 $\mathrm{cm}$. meja ini dirasa kurang nyaman karena kurang lebar untuk menulis, bahan meja ringan menyebabkan anak sering iseng mendorong - dorong meja menyebabkan meja jatuh sehingga pembelajaran kurang maksimal.

Meja pada gambar d. kelas 2 anak tunagrahita dengan panjang $86 \mathrm{~cm}$, lebar $40 \mathrm{~cm}$, tinggi $30 \mathrm{~cm}$, ukuran panjang ruang bawah $76 \mathrm{~cm}$, lebar ruang bawah 30 $\mathrm{cm}$, tinggi ruang bawah $23 \mathrm{~cm}$. Meja ini 
dirasa nyaman apabila digunakan oleh satu siswa namun bila di gunakan oleh lebih dari satu siswa akan terasa sempit. Bahan yang digunakan juga terbuat dari kayu yang bagus sehingga siswa dapat memanfaatkan meja dengan bijak tidak untuk bermain - main dengan temannya. Pembelajaran dengan menggunakan meja ini lebih baik.

Semua meja yang ada di kelas tunagrahita di SLB Putra Mandiri Kawunganten berbeda tidak ada yang sama Pada gambar b. kelas 4 dan 5, meja menempel pada kursi namun dirasa kurang nyaman Karena posisi meja yang berada disamping bukan di depan kursi sehingga menyulitkan siswa dalam menulis. Begitu pula dengan gambar a, c, dan d kelas anak tunagrahita, semua meja lesehan tanpa kursi. Meja tersebut dirasa lebih nyaman dari pada meja pada gambar b. anak kelas 4 dan 5 tunagrahita. Karena ukuran dan bahan meja yang ringan meyebabkan siswa sering iseng mendorong - dorong meja sehingga kelas sering gaduh dan meja roboh. Tak jarang meja dikelas tunagrahita ini sering rusak.

Menurut Peraturan Menteri Pendidikan Nasional nomor 3 tahun 2009 tanggal 29 Januari 2009 tentang standar / spesifikasi teknis pembangunan / rehabilitasi gedung dan meubelair sekolah dasar bahwa meja siswa tunggal dengan ukuran Panjang $60 \mathrm{~cm}$, lebar $55 \mathrm{~cm}$, tinggi $65-71 \mathrm{~cm}$. sedangkan untuk meja siswa ganda dengan ukuran Panjang $120 \mathrm{~cm}$, Lebar $55 \mathrm{~cm}$ dan tinggi $65-71 \mathrm{~cm}$. Peraturan Menteri Pendidikan Nasional Republik Indonesia Nomor 33 tahun 2008 tentang standar sarana dan prasarana untuk Sekolah Dasar Luar Biasa (SDLB), Sekolah Menengah Pertama Luar Biasa (SMPLB), dan Sekolah Menengah Atas Luar Biasa (SMALB) menerangkan tentang standar meja peserta didik kuat, stabil, aman, dan mudah dipindahkan oleh peserta didik. Ukuran sesuai dengan kelompok usia peserta didik dan mendukung pembentukan postur tubuh yang baik. Desain memungkinkan kaki peserta didik masuk dengan leluasa kebawah meja. Berdasarkan pengamatan - pengamatan di SLB X, hasil wawancara dengan pihak sekolah serta melihat Peraturan Menteri mengenai aturan standar meja maka re-desain meja untuk peserta didik tunagrahita SLB Putra Mandiri Kawunganten adalah sebagai berikut:

Rancangan usulan meja

\section{Tampak Depan}

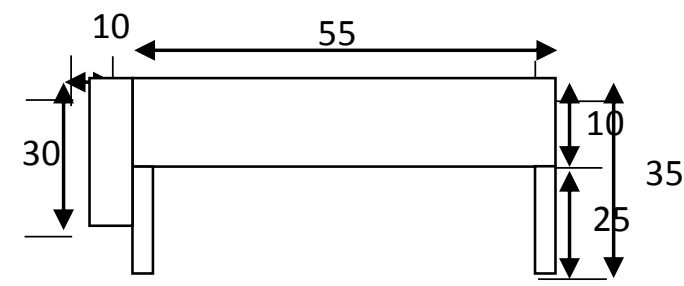

\section{Tampak belakang}

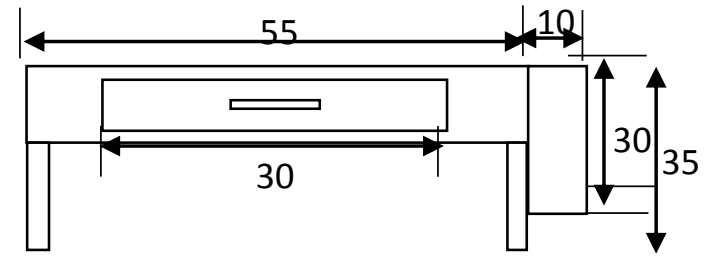

3. Tampak atas

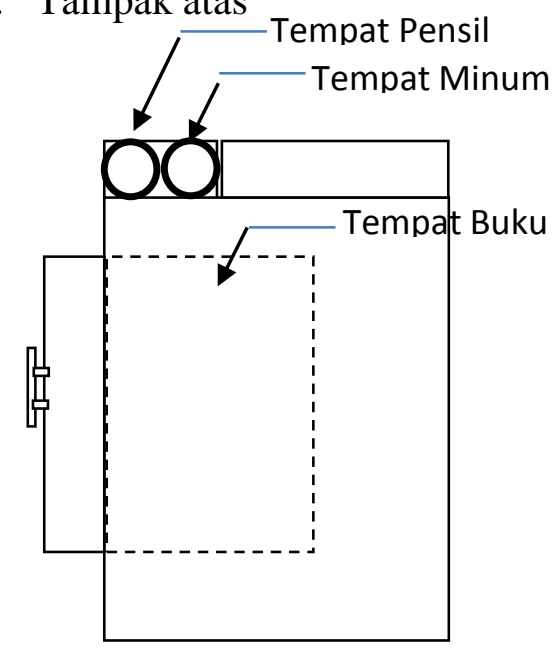




\section{Samping kiri}

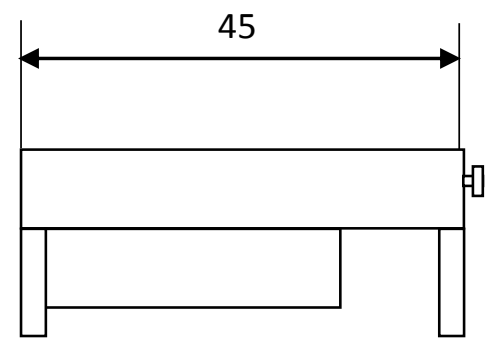

5. Samping kanan

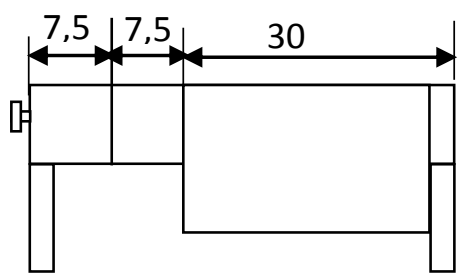

\section{Kesimpulan}

Dari data yang diolah, maka analisis redesain meja untuk keamanan dan kenyamanan peserta didik yaitu dengan menambahkan laci dibawah meja yang sudah dirancang sebagai tempat untuk menaruh buku ditepi atas sebelah kanan terdapat tempat menyimpan botol minum dan pensil serta alat tulis lain. Disamping meja terdapat tempat tas, sehingga semua peralatan sekolah anak terkumpul di satu tempat. Meja dibuat dengan ukuran panjang $55 \mathrm{~cm}$, lebar $45 \mathrm{~cm}$, tinggi $35 \mathrm{~cm}$. panjang ruang bawah $50 \mathrm{~cm}$, lebar ruang bawah $30 \mathrm{~cm}$, tinggi ruang bawah $25 \mathrm{~cm}$. Meja ini memiliki kolong meja yang luas sehingga kaki leluasa gerak di bawah meja . Re-desain meja ini di buat tanpa kursi karena peserta didik dan guru lebih senang duduk dikarpet sehingga pembelajaran terasa santai dan nyaman. bahwa:

Dari hasil analisis dapat disimpulkan

1. Meja bagi peserta didik di SLB Putra Mandiri Kawunganten belum sesuai untuk kebutuhan belajar peserta didik tunagrahita.

2. Meja anak tunagrahitan yang ada di SLB Putra Mandiri Kawunganten jumlahnya sedikit dengan desain yang berbeda-beda.
3. Beberapa anak belajar sambil tiduran karena tidak kebagian meja dan meja yang ada ukurannya kecil sehingga peserta didik tidak nyaman dalam belajar.

4. Peralatan sekolah peserta didik sering tececer dan tertukar dengan teman lainnya karena meja yang digunakantidak ada tempat untuk menaruh peralatan sekolah

5. Desain meja usulan dirancang untuk memenuhi kebutuhan, kuat, stabil, aman, dan mudah dipindahkan oleh peserta didik. Ukuran sesuai dengan kelompok usia peserta didik. Desain memungkinkan kaki peserta didik masuk dengan leluasa ke kolong meja

\section{Daftar Pustaka}

Al Khakim, A; Prakosha, D; Mimawanto, D.A. (2017). Aksesbilitas bagi anak berkebutuhan khusus dalam lingkup pendidikan sekolah inklusi di karisidenan Surakarta. Indonesia journal of disability studies (IJDS). 4(1). 16-18

Bandi Delphie (2006:2) perkembangan anak tunagrahita, Bandung: PT Refika Aditama

E. Kosasih. (2012) . Cara bijak memahami anak berkebutuhan khusus. Bandung :Yrama Widya

Jefri, T. (2016). Aksesbilitas sarana dan prasarana bagi penyandang tunadaksa di universitas brawijaya. IJDS. 3 (1). 16-25

Widi, N.A; Nirwansyah, R. (2013). Penerapan aksesbilitas pada desain fasilitas pendidikan sekolah luar biasa. Jurnal sains dan seni pomits. 2. 2

Nurmianto, E. (2008). Ergonomi konsep dasar dan aplikasinya. Edisi kedua. Jakarta: Guna Widya

Harahap,P.; Huda, L.N.; Pujangkoro, S.A. (2013). Analisis ergonomic redesain meja dan kursi siswa sekolah dasar. E-jurnal industry FT USU. 3.2

Peraturan Menteri Pendidikan Nasional Nomor 3 tahun 2009 tanggal 29 januari 2009 tentang standar / spesifikasi teknis 
IJDS 2018; Vol. 5 No. 1, May2018, pp.145-151

ISSN: $2355-2158$

pembangunan / rehabilitasi gedung dan meubelair sekolah dasar

Peraturan Menteri Pendidikan Nasional Republik Indonesia Nomor 33 tahun 2008 tentang standar sarana dan prasarana untuk Sekolah Dasar Luar Biasa (SDLB), Sekolah Menengah Pertama Luar Biasa (SMPLB), dan Sekolah Menengah Atas Luar Biasa (SMALB) 